\title{
ESTIMATION OF FAECAL FAT CONTENT OF JUNGLE CAT (FELIS CHAUS), FISHING CAT (PRIONAILURUS VIVERRINUS) AND GRAY LANGUR (SEMNOPITHECUS SP.), AND ITS COMPARATIVE VARIATIONS WITH RESPECT TO THEIR CAPTIVE AND WILD HABITAT
}

\author{
T. CHATTERJEE ${ }^{1 *}$, N. R. CHOWDHURY ${ }^{2}$, R. MUKHERJEA $^{3}$, \\ A. MAITY ${ }^{2}$ AND P. K. DAS ${ }^{4}$
}

\begin{abstract}
${ }^{1}$ Alipore Zoological Garden, Kolkata-700 027, West Bengal, India
${ }^{2}$ Department of Veterinary Biochemistry, West Bengal University of Animal and Fishery Sciences, Kolkata 700 037, West Bengal, India

${ }^{3}$ Veterinary Clinics, West Bengal University of Animal and Fishery Sciences, Kolkata-700 037 , West Bengal, India

${ }^{4}$ Department of Veterinary Physiology, West Bengal University of Animal and Fishery Sciences, Kolkata-700 037, West Bengal, India
\end{abstract}

\begin{abstract}
Blood collection from wildlife is not always feasible due to various types of risks and hazards. Whereas, the collection of faeces from the wildlives is feasible in any condition (free-range system or captive) to assess their health condition by estimating the faecal fat percentage and the acid steatocrit percentage. As such, faecal materials of the jungle cat (Felis chaus), fishing cat (Prionailurus viverrinus) and gray langur (Semnopithecus sp.) were collected from both the captive and the wild environment of the Alipore Zoological Garden, Kolkata. The study exhibited significantly $(P \leq 0.01)$ higher fat percentage in the jungle cat and fishing cat in wild and captive environment, whereas gray langur did not show any changes of fat percentage in their faeces. The results indicated the quicker adaptability of the gray langurs in their new habitats with respect to that of the jungle cats and fishing cats. The study also indicated that faecal fat content may be a good indicator about the physiological status of wild animals. Thus the method can be used as a reference value by which the clinician can assess better the diagnostic know-how.
\end{abstract}

Key words: Acid steatocrit, Faecal fat content, Fishing cat, Gray langur, Jungle cat

\section{INTRODUCTION}

Capability to absorb nutrients and energy from the feed determines an Animal's health condition, necessary for maintenance, growth, signaling and reproduction (Becker et al., 2012; Celi et al., 2017). It also accounts for the proper immunity and mental well-being of that animal as well (FAO, 2012). Assessment of intestinal integrity is thus essential to understand the health condition such as gain of body weight etc. of that animal (Tardelli et al., 2013;
Phuapradit et al., 2015). In case of wild animals maintained in captivity, it is more necessary to study the intestinal parameters as they are being kept in such a habitat which is having a significant difference from their natural habitat. To understand the aforesaid conditions, assessing the faecal properties and parameters of those animals can be done. Estimation of fat percentage in faeces can help to understand numerous aspects, such as ideas of animal's 
utilization of fat from the provided feed, (beneficial to maintain its proper physiology), nutrition of the animal and status of adaptability of the animal in captive life than that of their wildlife conditions (Wolfensohn et al., 2018). Any alteration of faecal fat percentage may be a sign of some sort of gastric disorders, due to gastric pathogens and gut-associated organs like liver, pancreas etc. (Girish et al., 2009; Erchinger et al., 2017; Kasýrga, 2019). Little studies on such parameters have been done before. So such study can help to create a reference value of the faecal fat content of the wild animals to be used as a foremost basic test to get a glimpse of their captive and ideal condition. All these points were also satisfactory for the comparative study. Hence, the preset study of faecal fat percentage of jungle cat (Felis chaus), fishing cat (Prionailurus viverrinus) and gray langur (Semnopithecus sp.) of both wildlife and captive life and their comparative assessments were done.

\section{MATERIALS AND METHODS}

Sample collection: Faecal samples $(n=10)$ were collected from jungle cats, fishing cats and gray langurs at the Alipore Zoological Garden, Kolkata which were remained in captive condition as well as rescued from the outskirts jungles of various districts of West Bengal. During the study, the diet of jungle cat, fishing cat and gray langur were provided as formulated by an animal dietician, in the Alipore Zoological Garden. Jungle cat was mainly provided with minced chicken@700 g/day. While a fishing cat provided with fish, preferably lata fish (Channa punctata)@750 g/day. Langurs was provided with a diet of $150 \mathrm{~g}$ of sweet fruits, $100 \mathrm{~g}$ of bread, $200 \mathrm{~g}$ of bananas, $200 \mathrm{~g}$ of red potatoes, $200 \mathrm{~g}$ of carrots (Das et al., 2013).

Faecal samples from the wild ones (rescued) were taken in sterile sample vials. Faecal samples were taken just after their rescue operation. Samples were further taken after 24 hours from rescue and also from the captive animals in the zoo. Then gathered samples were being assessed within 72 hours of collection (Meitern et al., 2016).

Acid steatocrit procedure: The Acid steatocrit procedure was being followed to estimate the faecal fat percentage (Bijoor et al., 2004). The procedure was as follows: $500 \mathrm{mg}$ of stool / faeces was diluted at a 1:3 ratio with double distilled water and poured into a test tube. It was then homogenized using a vortex. $500 \mu \mathrm{L}$ of the homogenized stool was pipetted into another test tube and $100 \mu \mathrm{L}$ of 5 molar perchloric acid $\left(\mathrm{HClO}_{4}\right)$ was added. Again the mixture was mixed using a vortex. After that, the mixture was aspirated into a capillary tube. One end of the capillary tubes was sealed with agarose. The capillary tubes were then centrifuged at $13000 \mathrm{rpm}$ for 15 minutes. This resulted to give a fatty layer on the topmost layer of the mixture which was then calculated with a focusing magnifier and a scale. Solids were deposited at the bottom of capillary tube. Faecal fat content was estimated by the following formulae:

$$
\text { Acid steatocrit } \%=\frac{\text { Fatty layer }}{\text { (Fatty later+Solid layer })} \times 100
$$

Faecal fat $=-0.43+\{0.45 \times($ acid steatocrit $\%)\} g / 24 \mathrm{~h}$

Statistical analyses: Acid steatocrit and faecal fat content were statistically analysed using Univariate Linear Model withone-way ANOVA and homogenous subsets were obtained with the help of Post Hoc Test (Duncan Multiple Range Test) in IBM SPSS Software V2.0.

\section{RESULTS}

Compared value of acid steatocrit (in percentage) and faecal fat content (g/24hrs) showed significantly $(\mathrm{P} \leq 0.01)$ higher in captive condition in jungle cat and fishing cat (Table 1). The values were lowest just after rescue than after 24 hours of rescue. No such variation has been found in the faecal sample of common gray langur in captivity and after recued. 
Table 1. Comparative studies (mean \pm standard error) of faecal samples derived from jungle cat, fishing cat and common gray langur

\begin{tabular}{|c|c|c|c|c|}
\hline \multirow[t]{3}{*}{ Animals } & \multicolumn{3}{|c|}{ Source of the faecal samples } & \multirow[t]{3}{*}{$P$ values } \\
\hline & \multirow{2}{*}{$\begin{array}{c}\text { Captive/Zoo } \\
(n=10)\end{array}$} & \multicolumn{2}{|c|}{ Free range/wild } & \\
\hline & & $\begin{array}{c}\text { Just after rescue } \\
(\mathrm{n}=10)\end{array}$ & $\begin{array}{l}\text { After } 24 \text { hours of } \\
\text { rescue }(n=10)\end{array}$ & \\
\hline \multicolumn{5}{|l|}{ Jungle cat } \\
\hline Acid steatocrit $\%$ & $9.73^{\mathrm{a}} \pm 0.37$ & $5.72^{\mathrm{c}} \pm 0.42$ & $8.35^{\mathrm{b}} \pm 0.39$ & $0.00^{*}$ \\
\hline Faecal fat content $(\mathrm{g} / 24 \mathrm{~h})$ & $4.01^{\mathrm{a}} \pm 0.14$ & $2.15^{\mathrm{c}} \pm 0.19$ & $3.33^{\mathrm{b}} \pm 0.18$ & $0.00^{*}$ \\
\hline \multicolumn{5}{|l|}{ Fishing cat } \\
\hline Acid steatocritcrit $\%$ & $17.93^{\mathrm{a}} \pm 0.84$ & $11.04^{\mathrm{c}} \pm 0.32$ & $14.39^{b} \pm 0.17$ & $0.00^{*}$ \\
\hline Faecal fat content $(\mathrm{g} / 24 \mathrm{~h})$ & $7.65^{\mathrm{a}} \pm 0.38$ & $4.55^{\mathrm{c}} \pm 0.14$ & $6.05^{\mathrm{b}} \pm 0.08$ & $0.00^{*}$ \\
\hline \multicolumn{5}{|l|}{ Common gray langur } \\
\hline Acid steatocrit $\%$ & $15.01 \pm 0.45$ & $14.56 \pm 0.31$ & $14.64 \pm 0.29$ & 0.64 \\
\hline Faecal fat content $(\mathrm{g} / 24 \mathrm{~h})$ & $6.33 \pm 0.20$ & $6.13 \pm 0.14$ & $6.16 \pm 0.13$ & 0.64 \\
\hline
\end{tabular}

${ }^{*} \mathrm{P}<0.01$, Means having different superscript in the same row did not differ signifantly

\section{DISCUSSION}

Faecal fat percentage estimation is one of the most important parameters to study the intestinal integrity and condition of an animal. As mentioned earlier, the study of intestinal integrity gives an idea not only about the physiological and behavioural aspect of the animal but also the adaptability of that animal in a habitat other than their natural one. Fat percentage or fat content of the faecal sample depends on the type of feed, utilisation of the fat from the feed and physiology of internal organs (Rose et al., 2015).

Chicken is a type of lean meat with a very low percentage of fat within it which was provided to the jungle cat. While lata fish contains a bit more of essential lipids, provided to the fishing cat. It may be the cause of presence of more amount of faecal lipid content in fishing cat.

Different level of faecal fat percentage of jungle cat and fishing cat may be due to the difference in their diets in wild conditions and captive conditions. Wild conditions provide them with diversified diets. But, in captive conditions, they are maintained with a specific diet. In case of gray langur, the non-significantly different variation of faecal fat percentage indicated that they can adapt quickly in their new habitat. Also, the diet of the langurs in wildlife and captive life have similarities, which may be the reason to reflect these results.

Faecal fat percentage may alter due to various reasons. One of the reasons is the animal's capability to adapt to a new habitat/captive life within the zoo, leading to physiological and digestive changes (Jones et al., 2018). The presence of gastro-intestinal pathogens such as Giardia spp., Coccidia (Isospora spp.) etc. affects the absorption of fat molecules from the intestine (Shea-Donohue et al., 2017). Ageing of the animal is also responsible for the degree of the absorption of fat molecules from the 
intestine (Gong and Muzumdar, 2012). Hepatic and pancreatic insufficiency, other diseases related to the liver and pancreas may alter fat digestion within the alimentary canal (Catanzaro et al., 2016; Storck et al., 2019).

The study also indicated the intestinal integrity of the jungle cat, fishing cat and gray langur which will be helping out to understand the condition of those animals in a captive condition and further clinical correlations will help the zoo personnel, animal handlers and the zoo veterinarians to understand their health condition and improve their adaptability in the zoo or any captive life by better managemental measures.

Also, there are no established reference values of faecal fat content of wild animals. This study has pointed out to put up reference values of faecal fat content of the jungle cat, fishing cat and gray langur in captive conditions. A comparison of faecal fat content of these animals

\section{REFERENCE}

Becker NI, Encarnação JA, Kalko EK and Tschapka M, 2012. The effects of reproductive state on digestive efficiency in three sympatric bat species of the same guild. Comp Biochem Physiol A Mol Integr Physiol, 162(4): 386-390, doi: 10.1016/j.cbpa.2012.04.021

Bijoor AR, Geetha S and Venkatesh T, 2004. Faecal fat content in healthy adults by the 'Acid Steatocrit Method'. Indian J Clin Biochem, 19: 20-22, doi: 10.1007/BF02894252

Catanzaro R, Cuffar B, Italia A and Marotta F, 2016. Exploring the metabolic syndrome: nonalcoholic fatty pancreas disease. World $\mathrm{J}$ Gastroenterol, 22(34): 7660-7675, doi: 10.3748/ wjg.v22.i34.7660

Celi P, Cowieson AJ, Fru-Nji F, Steinert RE, Kluenter AM et al., 2017. Gastrointestinal functionality in animal nutrition and health: new opportunities for sustainable animal production. Anim Feed Sci Technol, 234: 88-100, doi: 10.1016/j.anifeedsci.2017.09.012 in captivity with that of wild rescued was also drawn. The study has aimed to create further investigations of the rest of the wild and captive animals to establish the reference values of faecal fat content which can be utilized by the zoo authorities, zoo and wildlife veterinarians and workers as a basic preliminary test to assess the physiological and psychological conditions primarily. It can also be used as a routine test for the captive animals to investigate their physiological well-being, especially the gut environment of the animals, as the gut physiology depends upon the gut pathogens.

\section{ACKNOWLEDGMENT}

Special thanks are extending to Mr. Asis $\mathrm{Kr}$. Samanta, Director, Zoological Garden Alipore, Kolkata for providing samples and Dr. Kalyan Chakraborty, former Deputy Director, Govt. of West Bengal, ARD Department for the encouragement of the work.

Das A, Saini M, Dutta N, Sharma K, Saha SK et al., 2013. Standardization of Animal Diets in Indian Zoos, Central Zoo Authority, New Delhi and Indian Veterinary Research Institute, Izatnagar243122 (UP), Printing Palace, Tiwari Market, Janakpuri, Bareilly, http://cza.nic.in/ uploads/documents/publications/english/ standietainmal.pdf [1 September 2020]

Erchinger F, Engjom T, Jurmy P, Tjora E, Gilja OH et al., 2017. Fecal fat analyses in chronic pancreatitis importance of fat ingestion before stool collection. PLoS One, 12(1): e0169993, doi: 10.1371/journal.pone.0169993

FAO, 2012. Impact of animal nutrition on animal welfare - Expert Consultation 26-30 September 2011 - FAO Headquarters, Rome, Italy. Animal Production and Health Report, No. 1, Rome, http://www.fao.org/3/i3148e/i3148e00.htm

Girish BN, Rajesh G, Vaidyanathan K and Balakrishnan V, 2009. Fecal elastase 1 and acid steatocrit estimation in chronic pancreatitis. 
Indian J Gastroenterol, 28(6): 201-205, doi: $10.1007 / \mathrm{s} 12664-009-0079-\mathrm{z}$

Gong $\mathrm{Z}$ and Muzumdar RH, 2012. Pancreatic function, type 2 diabetes, and metabolism in aging. Int $\mathrm{J}$ Endocrinol, 2012(11): 320482, doi: 10.1155/ 2012/320482

Jones SKC, Munn AJ and Byrne PG, 2018. Effect of captivity on morphology: negligible changes in external morphology mask significant changes in internal morphology. R Soc Open Sci, 5(5): 172470, doi: 10.1098/ rsos. 172470

Kasırga E, 2019. The Importance of stool tests in diagnosis and follow up of gastrointestinal disorders in children. Turk Pediatri Ars, 54(3): 141-148, doi: 10.14744/Turk Pediatri Ars. 2018.00483

Meitern R, Lind MA, Karu U and Hõrak P, 2016. Simple and noninvasive method for assessment of digestive efficiency: validation of fecal steatocrit in greenfinch coccidiosis model. Ecol Evol, 6(24): 8756-8763, doi: 10.1002/ ece 3.2575

Phuapradit P, Narang A, Mendonca P, Harris DA and Baum JD, 2015. The steatocrit: A simple method for estimating stool fat content in newborn infants. Arch Dis Child, 56: 725-728, doi: 10.1136/adc.56.9.725

Rose C, Parker A, Jefferson B and Cartmell E, 2015. The characterization of faeces and urine: A review of the literature to inform advanced treatment technology. Crit Rev Environ Sci Technol, 45(17): 1827-1879, doi: 10.1080/ 10643389.2014.1000761

Shea-Donohue T, Qin B and Smith A, 2017. Parasites, nutrition, immune responses and biology of metabolic tissues. Parasite Immunol, 39(5): e12422, doi: 10.1111/pim.12422

Storck LJ, Imoberdorf R and Ballmer PE, 2019. nutrition in gastrointestinal disease: liver, pancreatic, and inflammatory bowel disease. J Clin Med, 8(8): 1098, doi: 10.3390/jcm8081098

Tardelli ACS, Camargos PAM, Penna FJ, Sarkis PFB and Guimarães EV, 2013. Comparison of diagnostic methods for pancreatic insufficiency in infants with cystic fibrosis. J Pediatr Gastr Nutr, 56(2): 178-181, doi: 10.1097/ MPG.0b013e31826f2b71

Wolfensohn S, Shotton J, Bowley H, Davies S, Thompson S et al., 2018. Assessment of welfare in zoo animals: towards optimum quality of life. Animals (Basel), 8(7): 110, doi: 10.3390/ ani8070110. 